\title{
Electronic Health Records and User Participation: Digital Natives versus Digital Immigrants
}

\author{
Deanna House ${ }^{1} \&$ Rajat Mishra ${ }^{2}$ \\ ${ }^{1}$ Management Information Systems Department, Ohio University, Athens, Ohio, USA \\ ${ }^{2}$ Nelson Rusche College of Business, Stephen F. Austin State University, Nacogdoches, Texas, USA \\ Correspondence: Deanna House, Management Information Systems, Ohio University, Copeland Hall 234, 1 \\ Ohio University; Athens, Ohio, USA. Tel: 1-740-593-1599. E-mail: housed2@ohio.edu
}

Received: April 11, 2015

doi:10.5539/ijbm.v10n7p31

\begin{abstract}
The need for clarity in the healthcare management is a matter of frequent discussion and concern among healthcare professionals, practitioners, patients and academicians. Electronic Health Records would provide clarity, transparency, interoperability and transferability in the health care information and data of the patients. It will also reduce the human mistakes and will reduce the likelihood of wrongly reading or interpreting the information. This paper introduces this useful concept and links it to the two classes of health care practitioners'digital natives' and 'digital immigrants'. The paper further identifies and discusses the relationship between user participation and system success and analyses the impact of moderation by digital natives and digital immigrants. The paper draws evidences from the existing state of literature to propose the relationships. Implications of the research to the practitioners and researchers are discussed.
\end{abstract}

Keywords: electronic health records, EHR, user acceptance, user participation, digital natives, digital immigrants, implementation success

\section{Introduction}

An electronic health record (EHR) is a complete record of a patient's healthcare; including workflow surrounding the patient's care (Burke \& Weill, 2009). According to National Alliance for Health Information Technology, the official definition of an electronic health record is: "an electronic record of health-related information on an individual that conforms to nationally recognized interoperability standards and that can be created, managed, and consulted by authorized clinicians and staff across more than one health care organization." (p. 6). EHR is capable of gathering patient data that can be easily exchanged from provider to provider, reporting data to public health agencies, and quantifying process improvements and outcomes (DeVore et al., 2007).

The use of EHRs has increased rapidly, according to the 2013 National Ambulatory Medical Care Survey (Hsiao \& Hing, 2014). The percentage of office-based physicians using EHRs in 2013 was 78\% (compared to 18\% in 2001) (Hsiao \& Hing, 2014). The government has indicated that EHRs are a key tool in improving the nation's healthcare and has put forth an incentive program to encourage the use of it (DeSalvo, 2014). This initiative has gotten the attention of healthcare organizations; with many scrambling to put software into place. Prior to the federally-mandated electronic health record, medical organizations were beginning to implement systems for reasons such as multiple site access, increased secure storage, and rapid search capabilities (Lim et al., 2008). The electronic health record is meant to assist both physicians and patients. One area of EHRs that has been of particular concern is patient safety.

Rising costs, coordination, and medical errors are all legitimate issues faced by healthcare systems (Rada, 2008). Electronic medical records are thought to be the panacea for dealing with these issues. However, they have not been associated with higher quality care (Kazley \& Ozcan, 2008). EHR projects are typically large-scale projects that are both organizationally and culturally transforming (Smaltz \& Berner, 2007). The organizational change that occurs in the fallout of an implementation can be challenging. It is important to have processes in place that are complimentary to the electronic health record software implemented.

The introduction of an electronic health record system may be cumbersome or cause workarounds that occur outside of the system; thus leading to a lack of compliance (Saigh et al., 2006). These workarounds can also be 
the result of poorly designed technology/system and the human technology interaction (Fuji \& Galt, 2008). For example, a paper form may have fields in place that no longer pertain to an electronic version of the form. The lack of user involvement in the system can be detrimental to its success. The users are process-oriented and need guidance during requirements gathering to ensure that the system design is conducive to a more efficient process. To help facilitate this process, it is imperative to determine the barriers associated with the implementation of electronic health record software to help assist with the reluctance among physicians to implement the systems (Gagnon et al., 2009).

Electronic health records are technology-dependent. (Kluge, 2001). Depending on the technology in place, they are inherently difficult to share between organizations (Rada, 2008). Sorting out how everything will fit together can be a challenge. Designing a flexible system is pertinent so that future technology can be easily integrated (Davis, 1994). Electronic health records should not be a direct copy of paper-based records (Davis, 1994). Additionally, they should require less time to enter data than the paper-based method (Dick \& Steen, 1992). Ideally, the electronic health record will be portable and have a lifetime history of the patients (Dick \& Steen, 1992).

Managing the change in a strategic and participative manner can help smooth the transition associated with implementing a new technology (Haddad, 2002). Specifically, user involvement is an important aspect that must be addressed (Rahimi et al., 2009). Physicians and health care providers are important stakeholders in health care organizations and having their input prior to and during the implementation is key to any information technology implementation but particularly electronic health records (Palacio, 2010).

The effects of user participation and success have been identified in prior research. However, it is unknown how the generational gap affects the acceptance and success of an implementation. This is of particular interest for technologies such as electronic health records because there are many generations of doctors that are using these technologies. Prensky (2001) came up with the term 'digital native' to indicate those that were born into technology. He differentiates 'digital natives' from 'digital immigrants' by stating that digital natives like multi-tasking, instant gratification, and technology. 'Immigrants' are those that keep a foot in the past. There has been quite a debate amongst researchers as to the lack of empirical evidence that young people are more technologically advanced (Bennett et al., 2008). This research will determine if those that are classified 'natives' will affect the relationship between user participation and the system success of electronic health records.

The next section gives an overview to literature leading up to the model development. Subsequent sections provide the model, hypotheses, and predicted analysis. Lastly, future research directions are noted.

\section{Literature Review}

Research has been contradictory regarding electronic health records and productivity. An increase has been shown by Cheriff et al. (2010); particularly by adopters. According to a study by Sobol and Prater (2006), physicians in 2003 (versus 1994) deemed recordkeeping and patient/hospital information as two of the most important areas of savings due to computer adoptions. The verdict is still out as to whether or not electronic health records will be worth all of the potential extra time and effort. However, the adopters or 'digital natives' will likely be more open to using new systems and implementing new processes. They may also be more influential in the use of the system, thus influencing other users to use the system (Swanson, 1974).

Physician resistance has been cited as one of the greatest impediments to the implementation of computerized systems (Poon et al., 2004) and is perceived as one of the biggest challenges (Zandieh et al., 2008). As mentioned by Yarbrough and Smith (2007), physicians are often reluctant to use technologies that interrupt traditional practice processes. A 'digital native' might not be so ingrained in practice processes and therefore would be more flexible in a new system implementation. When those that grew up with technology begin to enter the workforce, resistance to computers and technology should subside (Smaltz \& Berner, 2007).

Resistance to the information system (Deutscher et al., 2008; Zandieh et al., 2008) has been noted as being a detriment to the success of electronic health record implementations. All physicians using the system with few instances of resistance can indicate that the implementation will be fairly problem-free (Kleaveland, 2008). One method of alleviating this resistance can be due to user participation. Having the entire hospital staff on board with the new system can help influence and lead to effective use of the system (Davidson \& Chismar, 2007).

User involvement from the very beginning of the project will help set the stage for a system implementation that has been given feedback on the processes (Lorenzi et al., 2009). This will help ensure that the transition from a paper-based process to an electronic system process will go smoothly. The terms user participation and user involvement have been used synonymously in the literature prior to Barki and Hartwick's (1989) paper. Barki 
and Hartwick (1989) suggested that user participation is used to refer to the "behaviors and activities" users "perform in the system development process" (p. 59). EHR implementations require large-scale changes. Concerns about decreases in productivity are rampant; particularly for those organizations that are moving from purely paper-based operations (Zandieh et al., 2008). However, seamless integration can be achieved with enterprise-wide system implementations, which will not only increase productivity but also eliminate counter-productive processes (Davenport, 1998).

Digital natives are differentiated as those that are born into technology and refers to those born in 1980 and beyond (Prensky, 2001). There has been concern that the term 'digital native' is derogatory and offensive to those that might have resource constraints (Brown \& Czerniewicz, 2010). However, this issue will not pertain to this research due to its technological focus. At the time of this writing, the majority of the literature on the digital native debate has been in relation to education. This research will be novel in that electronic health records are being implemented across the United States with users of every age, race, and background. Natives have been shown to have "sophisticated technological skills" (Margaryan et al., 2011) which should transform to the use of new technologies in the workforce.

There are many factors that ensure the success of the implementation of healthcare technology. The system surroundings, properties, technologies, and time-varying characteristics all play a part (Doebbeling \& Pekny, 2008). Additionally, the system should not be thought of as a product, but rather of the processes that the organization puts into place that is supported by technology (Shortliffe \& Blois, 2006). Restructuring processes prior to implementation will provide a forum for input from all system users and thus document the "why" behind a particular process which will eventually lead to an enriched understanding amongst all users. Successful implementation of a technological change can be measured by evaluating if the system improved certain areas such as efficiency, flexibility, cost, health and safety, and/or quality (Haddad, 2002). This research will take a multi-faceted approach to success and look at cost, time, performance, and benefits.

In regards to electronic health record system implementations, having a flexible approach to the eminent change can help simplify the complicated web of varying physician practices (Lorenzi et al., 2009). When implementing a new technology, particularly going from paper-based to electronic, having some methods of fallback on the old system can be pleasing to the users (McDermid et al., 2010). But the balance of falling back to the old system versus keeping the processes electronic can be detrimental to efficiency. Therefore, involving the users early on in the project should influence success. Overall, the research indicates that user participation will have a direct relationship on system success. Digital natives, due to their technological advancement, should be more adept at using the system. The next section introduces the research model and propositions.

\section{Propositions and Research Model}

The model below is broadened from a model showing the direct relationship between user participation and system success developed by McKeen et al. (1994). McKeen specifies user participation as a behavior. The direct effects of user participation on success have been shown to have a positive effect (He \& King, 2008; Lin \& Shao, 2000; Wong \& Tate, 1994; Doll \& Torkzadeh, 1989). Prior measures of user involvement on success have been weak; but bringing in multiple perspectives can add rigor to the measurement (Ives \& Olson, 1984).

Success has been measured in a variety of ways, but user satisfaction (Vadapalli \& Moore, 2000; Doll \& Torkzadeh, 1988) and performance (Hong \& Kim, 2002) are all-encompassing. Doll \& Torkzadeh (1988) state that user information satisfaction refers to a user's feelings towards a system. Keshavjee et al. (2001) came up with a measurement for success of an electronic medical record implementation. Thus proposition 1 states that user participation will have a positive influence on electronic health record success.

\section{P1: User participation will increase the electronic health record success.}

There are many factors that can moderate the relationship between user participation and system success (McKeen et al., 1994). As introduced in the literature review, digital natives are those that are born with technology and digital immigrants are those that are less familiar. Digital immigrants are individuals born in 1979 or earlier. Digital natives defined as those that are born in the year 1980 and later (Prensky, 2001). When a subject-matter expert such as a doctor or nurse makes a transition from a paper-based to an EHR system, it is likely that there will be a change in the relationship between user participation and system success. However, for digital natives, the relationship is predicted to be strengthened. 'Digital natives' are predicted to strengthen the relationship between user participation and system success.

P2a: Individuals that are digital natives will positively moderate the relationship between user participation and system success in that there will be an increased relationship between user participation and system success 


\section{among digital natives.}

It is predicted that digital immigrants will also moderate the relationship between user participation and system success. Digital immigrants are not particularly adept at learning new technologies (as opposed to digital natives) (Margaryan et al., 2011). Those that are lacking computer experience may not feel comfortable using the system and may feel threatened (DeVore et al., 2007). Therefore, the relationship between user participation and system success for digital immigrants is predicted to be moderated negatively.

P2b: Individuals that are digital immigrants will negatively moderate the relationship between user participation and system success in that there will be a decreased relationship between user participation and system success among digital immigrants.
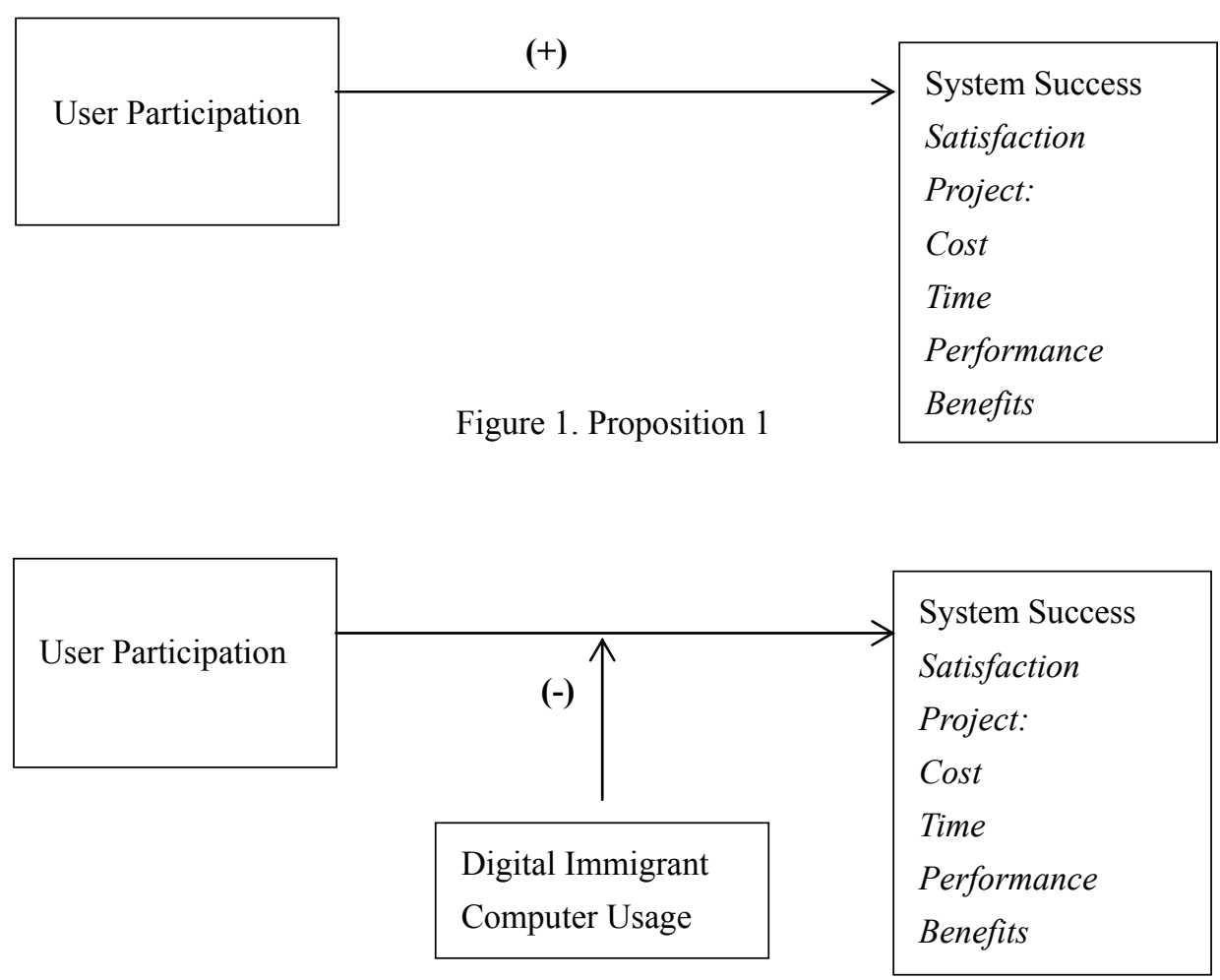

Figure 2. Proposition 2

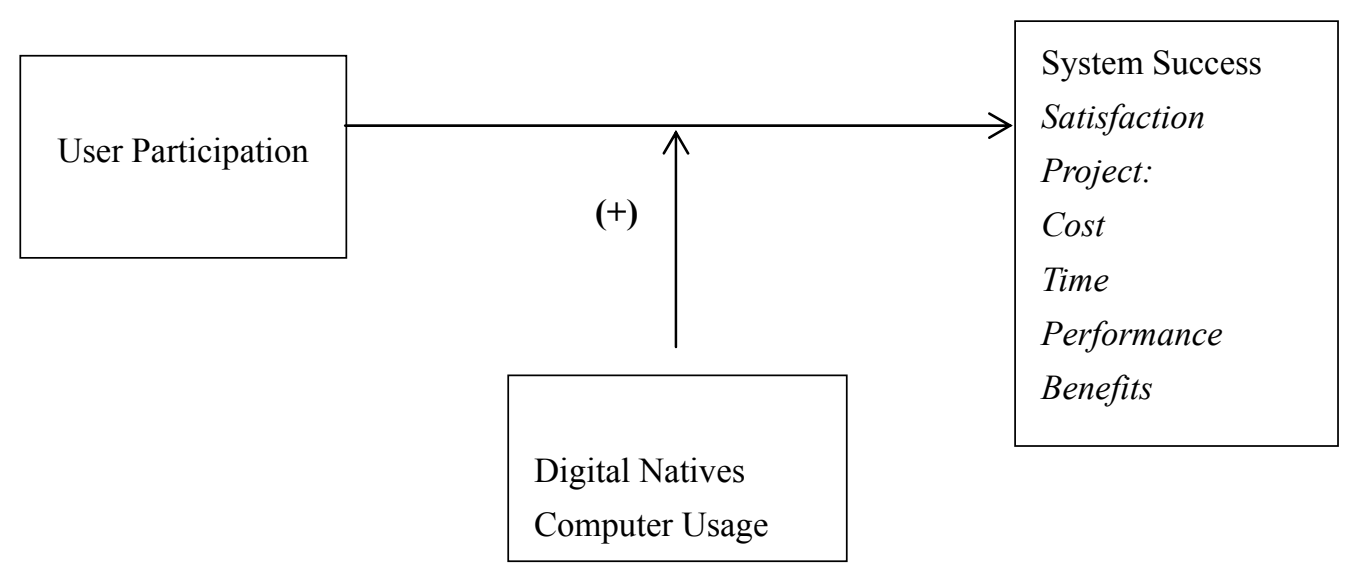

Figure 3. Proposition 3

\section{Implications for Practitioners/Academics}

This research has merit for both practitioners and academics. From a practical standpoint, the research will give 
those that are involved with electronic health record implementations information regarding system users. Bringing in digital natives to act as project champions may assist in nudging the digital immigrants in the right direction towards accepting the system. Healthcare costs are soaring and have been a huge matter of concern for all the parties involved. It will assist the doctors to see the records of the patients at a glance which will increase the efficiency of the work performance and avoid major issues when dealing within the constrained time to act on patients' treatment. This is also thought to be helpful for the patients where they can retrieve their health history with relatively higher degrees of easiness.

Additionally, assessing the underlying efficiencies of solving a business problem are required steps when implementing an information system such as an EHR. Getting the users involved in the processes early on will help ensure that the information system solution will make the process more efficient. While digital natives are predicted to increase the relationship between user participation and system success, it is still important to remember that user participation throughout the project will overall influence success.

From an academic standpoint, this research brings in a fresh relevant concept and a new terminology to information system implementation and seeks to delve further into finding out the reasons why systems are successful or unsuccessful. This research is unique to other information system implementations due generation gap that is currently present among physicians. Subsequent research on this topic will provide more insight as more 'natives' head out into the workforce.

\section{Future Research Directions}

An area of interest for future research is the integration of data once it is in a system. Data is not always in a usable format. Typically, a centralized repository is necessary so that it is possible to read and report on data as a whole. It is still fairly common for medical machines to have islands of information that need to be individually consulted (and/or printed). Healthcare professionals need to have a standard for data collection and acquisition (Fonseca et al., 2009).

There is a general lack of standards in health care management which creates issues with electronic health records. In order for electronic health records to increase in sophistication, a common set of terminology and standards must be developed (Lim et al., 2008). This will help alleviate issues associated with the difficulties integrating the different electronic health record systems. Having standards will also cut down on costs associated with interfaces and will allow for an easier transition into the next generation of electronic health records.

The consumer is not frequently considered in the literature surrounding electronic health records. The consumer can be considered a key stakeholder in the process of information exchange and it is pertinent to ensure that no negative consequences come about from said exchange (Fuji \& Galt, 2008). Research must be conducted to ensure that consumers are in fact also gaining from electronic health record implementations. As health care costs continue to rise, it is imperative that consumers receive quality care in an affordable manner.

\section{Conclusion}

This research is expected to add to the existing healthcare research benefiting both the practitioners and researchers. It indicates whether or not the 'digital natives' have an effect on electronic health record implementations. It is predicted that those born into technology will have less of an aversion to participating in the use of electronic health record software and thus the digital natives will have a positive effect of moderation. This will provide both practitioners and academicians will the knowledge that some users will not participate in the system unless forced.

The more that information technology practitioners and researchers know about underlying causes to resistance of electronic health records, the easier it will be to get everyone on board and using the system. The 'digital immigrants' are likely to be the ones who will act as a possible resistance to the EHR practice. This research aims to have served as one of the first stepping stones in identifying the advantage of the application of EHR with the discussion of the possible reasons of resistance especially from some quarters mostly identified as the 'digital immigrants'. The research opens up a wide room for future works in health care management pertaining to the usage of the software and computer systems to systematize and standardize, and better handling of the healthcare data for the reduction of cost, higher degrees of clarity and transparency among the healthcare firms and ultimately for the ease of the patients.

\section{References}

Ball, M. J., \& Collen, M. F. (1992). Aspects of the Computer-Based Patient Record. New York: Springer-Verlag New York, Inc. 
Barki, H., \& Hartwick, J. (1989). Rethinking the Concept of User Involvement. MIS Quarterly, 13(1), 53-63. http://dx.doi.org/10.2307/248700

Bennett, S., Maton, K., \& Kervin, L. (2008). The 'Digital Native' Debate: A Critical Review of the Evidence.

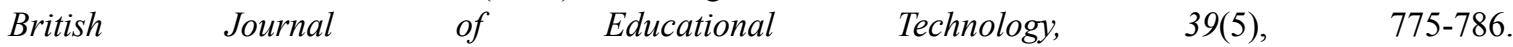
http://dx.doi.org/10.1111/j.1467-8535.2007.00793.x

Bhattacherjee, A., \& Hikmet, N. (2007). Physicians' Resistance Toward Healthcare Information Technology: A Theoretical Model and Empirical Test. European Journal of Information Systems, 16(6), 725-737. http://dx.doi.org/10.1109/hicss.2007.437

Brown, C., \& Czerniewicz, L. (2010). Debunking the 'Digital Native': Beyond Digital Apartheid, Towards Digital Democracy. Journal of Computer Assisted Learning, 26, 357-369. http://dx.doi.org/10.1111/j.1365-2729.2010.00369.x

Burke, L., \& Weill, B. (2009). Information Technology for the Health Professions. Upper Saddle River, New Jersey: Pearson Prentice Hall.

Cheriff, A. D., Kapur, A. G., Qiu, M., \& Cole, C. L. (2010). Physician Productivity and the Ambulatory EHR in a Large Academic Multi-Specialty Physician Group. International Journal of Medical Informatics, 79(7), 492-500. http://dx.doi.org/10.1016/j.ijmedinf.2010.04.006

Davenport, T. H. (1998). Putting the Enterprise into the Enterprise System. Harvard Business Review, 76(4), 121-131.

Davidson, E. J., \& Chismar, W. J. (2007). The Interaction of Institutionally Triggered and Technology-Triggered Social Structure Change: An Investigation of Computerized Physician Order Entry. MIS Quarterly, 31(4), 739-758.

Davis, M. W. (1994). Computerizing Healthcare Information: Developing Patient Information Systems. Chicago, Illinois: Probus Publishing Company.

DeSalvo, K. B. (2014). Survey Says: EHR Incentive Program is on Track. Health IT Buzz. Retrieved from http://www.healthit.gov/buzz-blog/from-the-onc-desk/survey-ehr-incentive-program

Deutscher, D., Hart, D. L., Diskstein, R., Horn, S. D., \& Gutvirtz, M. (2008). Implementing an Integrated Electronic Outcomes and Electronic Health Record Process to Create a Foundation for Clinical Practice Improvement. Physical Therapy, 88(2), 270-285. http://dx.doi.org/10.2522/ptj.20060280

DeVore, D., Price, C., \& Natzke, J. (2007). Preparing for Electronic Charting. Long-Term Living Magazine, 28-31.

Dick, R. S., \& Steen, E. B. (1991). The Computer-Based Patient Record: An Essential Technology for Healthcare. The Committee on Improving the Patient Record Division of Health Care Services. Washinton, D.C.: National Academy Press.

Doebbeling, B. N., \& Pekny, J. (2008). The Role of Systems Factors in Implementing Health Information Technology. Journal of General Internal Medicine, 23(4), 500-501. http://dx.doi.org/10.1007/s11606-008-0559-3

Doll, W. J., \& Torkzadeh, G. (1988). The Measurement of End-User Computing Satisfaction. MIS Quarterly, 12(2), 259-274. http://dx.doi.org/10.2307/248851

Doll, W. J., \& Torkzadeh, G. (1989). A Discrepancy Model of End-User Computing Involvement. Management Science, 35(10), 1151-1170. http://dx.doi.org/10.1287/mnsc.35.10.1151

Fonseca, T., Ribeiro, C., \& Granja, C. (2009). Vital Signs in Intensive Care: Automatic Acquisition and Consolidation into Electronic Patient Records. Journal of Medical Systems, 33, 47-57. http://dx.doi.org/10.1007/s10916-008-9163-7

Fuji, K. T., \& Galt, K. A. (2008). Pharmacists and Health Information Technology: Emerging Issues in Patient Safety. HEC Forum, 20(3), 259-275. http://dx.doi.org/10.1007/s10730-008-9075-4

Gagnon, M. P., Shaw, N., Sicotte, C., Mathieu, L., Leduc, Y., Duplantie, J., Maclean, J., \& Legare, F. (2009). Users' Perspective of Barriers and Facilitators to Implementing EHR in Canada: A Study Protocol. Implementation Science, 4(1), 20-27. http://dx.doi.org/10.1186/1748-5908-4-20

Haddad, C. J. (2002). Managing Technological Change: A Strategic Partnership Approach. Thousand Oaks, California: Sage Publications, Inc. 
He, J., \& King, W. R. (2008). The Role of User Participation in Information Systems Development: Implications from a Meta-Analysis. Journal of Management Information Systems, 25(1), 301-331. http://dx.doi.org/10.2753/mis0742-1222250111

Hong, K. K., \& Kim, Y. G. (2002). The Critical Success Factors for ERP Implementation: An Organizational Fit Perspective. Information \& Management, 40(1), 25-40. http://dx.doi.org/10.1016/s0378-7206(01)00134-3

Hsiao, C. J., \& Hing, E. (2014). Use and Characteristics of Electronic Health Record Systems Among Office-Based Physician Practices: United States, 2001-2013. NCHS Data Brief, 143, 1-8.

Ilie, V., Van Slyke, C., Courtney, J. F., \& Styne, P. (2009). Challenges Associated with Physicians' Usage of Electronic Medical Records. International Journal of Healthcare Information Systems and Informatics, 4(3), 38-54. http://dx.doi.org/10.4018/jhisi.2009070103

Ives, B., \& Olson, M. (1984). User Involvement and MIS Success: A Review of Research. Management Science, 30(5), 586-603. http://dx.doi.org/10.1287/mnsc.30.5.586

Kazley, A. S., \& Ozcan, Y. A. (2008). Do Hospitals with Electronic Medical Records (EMRs) Provide Higher Quality Care? An Examination of Three Clinical Conditions. Medical Care Research and Review, 65(4), 496-513. http://dx.doi.org/10.1177/1077558707313437

Keshavjee, K., Troyan, S., Holbrook, A. M., \& VanderMolen, D. (2001). Measuring the Success of Electronic Medical Record Implementation Using Electronic and Survey Data. Proceedings AMIA Annual Symposium. Washington, D.C.

Kleaveland, B. (2008). Making it to the EHR Promised Land. How to Solve Common EHR Adoption Problems. MGMA Connexion, 8(5), 42-45.

Kluge, E. W. (2001). The Ethics of Electronic Patient Records. New York: Peter Lang Publishing, Inc.

Lim, E. Y. S., Fulham, M., Feng, D. D. (2008). In Feng, D.D. (Ed.) Biomedical Information Technology (pp. 29-49). Burlington, Massachusetts: Elsevier.

Lin, W. T., \& Shao, B. B. M. (2000). The Relationship Between User Participation and System Success: A Simultaneous Contingency Approach. Information \& Mangement, 37(6), 283-295. http://dx.doi.org/10.1016/s0378-7206(99)00055-5

Lorenzi, N. M., Kouroubali, A., Detmer, D. E., \& Bloomrosen, M. (2009). How to Successfully Select and Implement Electronic Health Records (EHR) in Small Ambulatory Practice Settings. BMC Medical Informatics and Decision Making, 9, 15-27. http://dx.doi.org/10.1186/1472-6947-9-15

Margaryan, A., Littlejohn, A., \& Vojt, G. (2011). Are Digital Natives a Myth or Reality? University Students' Use of Digital Technologies. Computers \& Education, 56, 429-440. http://dx.doi.org/10.1016/j.compedu.2010.09.004

McDermid, D. C., Kristjanson, L. J., \& Spry, N. (2010). Factors Affecting the Sustainability of Computer Information Systems: Embedding New Information Technology into a Hospital Environment. International Journal of Healthcare Information Systems and Informatics, 5(1), 1-15. http://dx.doi.org/10.4018/jhisi.2010110301

McKeen, J. D., \& Guimaraes, T. (1997). Successful Strategies for User Participation in Systems Development. Journal of Management of Information Systems, 14(2), 133-150.

McLeod, Jr., A. J., \& Clark, J. G. (2009). Using Stakeholder Analysis to Identify Users in Healthcare Information Systems Research: Who is the Real User? International Journal of Healthcare Information Systems and Informatics, 4(3), 1-15. http://dx.doi.org/10.4018/jhisi.2009070101

National Alliance for Health information Technology. (2008). The National Alliance for Health Information Technology Report to the Office of the National Coordinator for Health Information Technology on Defining Key Health Information Technology Terms. Retrieved from http://healthit.hhs.gov/portal/server.pt?open=512\&objID=1239\&parentname=CommunityPage\&parentid=2 $2 \&$ mode $=2 \&$ in_hi_userid $=11113 \&$ cached $=$ true

Palacio, C., Harrison, J. P., \& Garets, D. (2010). Benchmarking Electronic Medical Records Initiatives in the U.S.: A Conceptual Model. Journal of Medical Systems, 34(3), 273-279. http://dx.doi.org/10.1007/s10916-008-9238-5

Poon, E. G., Blumenthal, D., Jaggi, T., Honour, M. M., Bates, D. W., \& Kaushal, R. (2004). Overcoming Barriers 
to Adopting and Implementing Computerized Physician Order Entry Systems in U.S. Hospitals. Health Affairs, 23(4), 184-190. http://dx.doi.org/10.1377/hlthaff.23.4.184

Prensky, M. (2001). Digital Natives, Digital Immigrants. On the Horizon, 9(5), 1-10. http://dx.doi.org/10.1108/10748120110424816

Rada, R. (2008). Information Systems and Healthcare Enterprises. Hershey, Pennsylvania: IGI Publishing.

Rahimi, B., Vimarlund, V., \& Timpka, T. (2009). Health Information Systems Implementation: A Qualitative Meta-Analysis. Journal of Medical Systems, 33(5), 359-368. http://dx.doi.org/10.1007/s10916-008-9198-9

Saigh, O., Triola, M. M., \& Link, R. N. (2006). Brief Report: Failure of an Electronic Medical Record Tool to Improve Pain Assessment Documentation. Journal of General Internal Medicine, 21(2), 185-188. http://dx.doi.org/10.1007/s11606-006-0256-z

Shortliffe, E. H., \& Blois, M. S. (2006). In E. H. Shortliffe, \& J. J. Cimino, (Eds.), Biomedical Informatics: Computer Applications in Health Care and Biomedicine (pp. 3-45). New York: New York: Springer Science + Business Media, LLC.

Smaltz, D. H., \& Berner, E. S. (2007). The Executive's Guide to Electronic Health Records. Chicago, Illinois: Health Administration Press.

Sobol, M., \& Prater, E. (2006). Differences in Computer Usage of U.S. Group Medical Practices: 1994 vs. 2003. $\begin{array}{lllll}\text { International Journal of Healthcare Information Systems, } 1(1), & 64-77 .\end{array}$ http://dx.doi.org/10.4018/jhisi.2006010105

Sridhar, V., Nath, D., \& Malik, A. (2009). Analysis of User Involvement and Participation on the Quality of IS Planning Projects. Journal of Organizational and End User Computing, 21(3), 80-98. http://dx.doi.org/10.4018/joeuc.2009070105

Swanson, E. B. (1974). Management Information Systems: Appreciation and Involvement. Management Science, 21(2), 178-188. http://dx.doi.org/10.1287/mnsc.21.2.178

Szabla, D. B. (2007). A Multidimensional View of Resistance to Organizational Change: Exploring Cognitive, Emotional, and Intentional Responses to Planned Change across Perceived Change Leadership Strategies, Human Resource Development Quarterly, 18(4), 525-558. http://dx.doi.org/10.1002/hrdq.1218

Vadapalli, A., \& Mone, M. A. (2000). Information Technology Project Outcomes: User Participation Structures and the Impact of Organization Behavior and Human Resource Management Issues. Journal of Engineering and Technology Management, 17(2), 127-151. http://dx.doi.org/10.1016/s0923-4748(00)00018-7

Wong, E. Y. W., \& Tate, G. (1994). A Study of User Participation in Information Systems Development. Journal of Information Technology, 9(1), 51-60. http://dx.doi.org/10.1057/jit.1994.6

Yarbrough, A. K., \& Smith, T. B. (2007). Technology Acceptance Among Physicians: A New Take on TAM. Medical Care Research and Review, 64(6), 650-672. http://dx.doi.org/10.1177/1077558707305942

Zandieh, S. O., Yoon-Flannery, K., Kuperman, G. J., Langsam, D. J., Hyman, D., \& Kaushal, R. (2008). Challenges to EHR Implementation in Electronic-Versus Paper-Based Office Practices. Journal of General Internal Medicine, 23(6), 755-761. http://dx.doi.org/10.1007/s11606-008-0573-5

\section{Copyrights}

Copyright for this article is retained by the author(s), with first publication rights granted to the journal.

This is an open-access article distributed under the terms and conditions of the Creative Commons Attribution license (http://creativecommons.org/licenses/by/3.0/). 